\section{Spicy Pepper Consumption and Preferences in the United States}

\author{
Jay M. Lillywhite ${ }^{1,3,6}$, Jennifer E. Simonsen ${ }^{1,4}$, \\ and Mark E. Uchanski ${ }^{2,5}$
}

AdDitional InDEX wORDs. chile, chili, hot, pungent peppers, purchasing

SUMMARY. Little data are publicly available about U.S. spicy pepper (Capsicum sp.) consumers and their type-specific preferences. This research adds to the body of knowledge surrounding the demand side of the U.S. spicy pepper market by providing exploratory data to examine U.S. consumer preferences as they relate to seven common spicy pepper types: cayenne (Capsicum annuum), habañero (Capsicum chinense), jalapeño (C. annuum), New Mexico-type long green and red $(C$. annuum), paprika (C. annuum), poblano/ancho (C. annumm), and serrano $(C$. annuиm) peppers. Data were collected using an online panel survey of 1104 consumers. Results suggest that jalapeño peppers were the most popular fresh spicy pepper purchased by participating food consumers. Paprika powder, a relatively mild spicy pepper product, was the most widely-consumed dried or ground pepper of the seven studied. Women appear more likely to be non-likers of spicy foods than men $(P \leq 0.05)$. Responses of this survey group suggest that many consumers enjoy spicy peppers and that consumption varies by pepper type. Finally, the most popular pepper types do not necessarily appear to be the "hottest" or "mildest" of those available in the market.

$S$ picy foods have been consumed by humans for centuries, although the heat contained in many plants is an adaptation meant to be a consumption deterrent (Rozin and Schiller, 1980). A food is categorized as spicy if it contains a chemesthetic irritant that causes a hot sensation; this irritant is often the chemical compound capsaicin (Rowland et al., 1983). Food scientists refer to the sensation caused by these irritants as pungency (Tornwall et al., 2012) and measure the associated heat level using Scoville heat units (SHU). The SHU has traditionally been measured using the human palette, but is now quantified via highperformance liquid chromatography (HPLC) and converted to SHU (Collins et al., 1995). Naturally occurring spicy foods can vary in pungency, and thus in their SHU. For example, bell peppers

Institutional Review Board (IRB) approval was received to obtain data from human subjects for this research project.

This research was made possible through the support of New Mexico State University's Agricultural Experiment Station.

${ }^{1}$ Department of Agricultural Economics \& Agricultural Business, New Mexico State University

${ }^{2}$ Department of Plant and Environmental Sciences, New Mexico State University

${ }^{3}$ Associate Professor

${ }^{4}$ Senior Research Specialist

${ }^{5}$ Assistant Professor

${ }^{6}$ Corresponding author. E-mail: lillywhi@nmsu.edu.
(Capsicum annuum) are not pungent $(\mathrm{SHU}=0)$, while the spicy pepper cultivar Trinidad Moruga Scorpion (Capsicum chinense) is extremely pungent and can measure more than 2 million SHU (Bosland et al., 2012). Any pepper type with $\geq 1$ SHU could be considered spicy. However, for this study, paprika (0-300 SHU), New Mexico long green or red chile (300-500 SHU), and poblano/ancho $(\approx 1369$ SHU) types were included as mild spicy peppers (Table 1 ).

While some people like spicy foods, others do not. Much research has explored the psychological and physiological reasons behind variations in preference toward spicy foods. When non-likers of spicy foods and likers of spicy foods both consumed jelly spiked with the same amount of capintense and less pleasant than likers. The results of this study suggest genetic factors may help explain differences in pungency preferences (Tornwall et al., 2012). Although some research suggests exposure can improve liking (Rozin and Schiller, 1980), other findings suggest no difference between "non-likers" and "likers" in their exposure to spicy foods when young (Tornwall et al., 2012). Likers of spicy foods may have thrill-seeking personality traits or derive pleasure from the fact that pungency only saicin, non-likers rated the jelly more appears harmful (Rozin and Schiller, 1980). Cultural influences (e.g., role models, early introduction) may also affect consumption of spicy foods (Ludy and Mattes, 2012).

Many spicy foods contain a wide array of possible spicy peppers. The general term spicy pepper is used to describe any number of peppers from the genus Capsicum with pungent types. These peppers are also known as hot, chili, chile, or pungent peppers [U.S. Department of Agriculture (USDA), 2008]. Pungent peppers should not be confused with mild or bell pepper types, also referred to as green, sweet, or nonpungent peppers (USDA, 2008). Since the term "chile" or "chile pepper" is also used to describe a subset of pungent pepper types (e.g., anaheim or long red/ green New Mexico-style chile peppers), the term "spicy pepper" will be used to describe pungent peppers as a whole throughout the remainder of this article.

In the United States, an increasing number of people are consuming foods made with spicy ingredients such as spicy peppers (e.g., Josiam and Monteiro, 2004). Per capita consumption of spicy peppers in the United States has more than doubled since 1980, but the United States is now a net importer of spicy peppers (Fig. 1). Although there are assuredly differences in the preferences of individuals regarding spicy foods, spicy/ hot flavors are increasingly appealing in the United States (King et al., 2010). Moreover, consumers appear to enjoy spicy peppers for their heat: consumers rank pungency as the most important quality factor when choosing spicy peppers (Mohammed et al., 1993).

At the national level, little to no purchase or consumption data are available for individual spicy pepper types (e.g., jalapeños, serranos). Data are often incomplete, no longer updated, or all spicy pepper types are combined as "chile peppers" (USDA, 2008). Thus, few studies have examined consumer demand for individual spicy pepper types. Previous research, however, has explored the import quantity changes of specific spicy pepper types after human infectious disease outbreaks (Klontz et al., 2010). Consumer shopping and type preferences for spicy peppers have also been explored in Mexico and Canada (Castellon-Martinez 
et al., 2012; Mohammed et al., 1993). Little data exist, however, to compare U.S. consumption trends by pepper type. One way to collect current consumer demand data are through the use of Web-based surveys.

Web-based surveys are becoming increasingly popular in market research as they present a number of advantages. Advantages include time and cost efficiency (Couper, 2001; Evans and Mathur, 2005; Miller and Dickson, 2001), flexibility in the way questions are presented (Couper, 2001; Evans and Mathur, 2005), and ability to reach a large segment of the population (Evans and Mathur, 2005; Sheehan, 2002). Although the methodology has advantages, it also has limitations, some of which are common

Table 1. Some common pepper types in the United States and their pungency in Scoville heat units (SHU) (Chile Pepper Institute, 2006; Coon et al., 2008; OrellanaEscobedo et al., 2012).

\begin{tabular}{lc}
\hline Pepper type & SHU \\
\hline Habañero & $150,000-210,000$ \\
Serrano & 25,000 \\
Chipotle & 23,115 \\
Cayenne & $8,500-23,000$ \\
Jalapeño & $4,000-50,000$ \\
Ancho & 1,369 \\
Poblano & 1,369 \\
New Mexico & $300-5,000$ \\
$\quad$ long green or red & \\
Paprika & $0-300$ \\
Bell & 0 \\
\hline
\end{tabular}

to other survey methodologies. Limitations of Web-based surveys, such as online panel surveys, include potential limited distribution or inability to reach all segments of the population (Miller and Dickson, 2001), difficulties in measuring representativeness of the sample/sampling frame (Miller and Dickson, 2001; Evans and Mathur, 2005; Wright, 2005), and other issues common with self-administered surveys, such as an inability to focus respondent attention on the survey task (Miller and Dickson, 2001). Despite some of these potential issues, this study aims to provide some of the first national data to explore U.S. consumer preferences as they relate to seven common spicy pepper types.

Stakeholders in the U.S. spicy pepper food chain need timely information about consumer preferences and shopping patterns to make informed production and marketing decisions. However, little market data are publically available about U.S. spicy pepper consumers; specifically, their demographics, what kinds of peppers they consume, and their shopping patterns. This article adds to the body of knowledge of demand for U.S. spicy peppers. We provide baseline data to explore U.S. consumer preferences as they relate to spicy peppers regardless of their source.

\section{Materials and methods}

An online panel survey was conducted on 3-7 Dec. 2012 to collect primary data regarding consumer pepper preferences and shopping behavior. The survey instrument, a 24page, 42-question questionnaire, was split into four sections to collect information on 1) consumers' fruit and vegetable purchases, 2) spicy pepper purchases, 3 ) chile pepper purchases and preferences, and 4) demographic characteristics of the respondent. Survey respondents were members of a group of online market research panels managed by Cint, an independent global market research corporation with U.S. offices in Atlanta, GA, and Los Angeles, CA. The market research company provided compensation to respondents for their participation in market research surveys. Survey respondents were required to be at least 18 years of age. A sample of 13,771 panelists (representative of the United States in terms of U.S. Census region of residence) were invited to participate in the survey via e-mail to meet a sample quota of 1000 respondents, and a total of 1104 responses were used in the analysis.

The scope of the survey and several key terms used in the survey instrument were defined for consumers. Survey participants were informed that the study was focused on shopping preferences for foods consumed at home, especially spicy peppers, explained as "spicy peppers come in a mix of types and colors. They can be used to add heat (spiciness) and flavor to foods." Respondents were provided with information regarding the term "chile pepper" (as it is used in

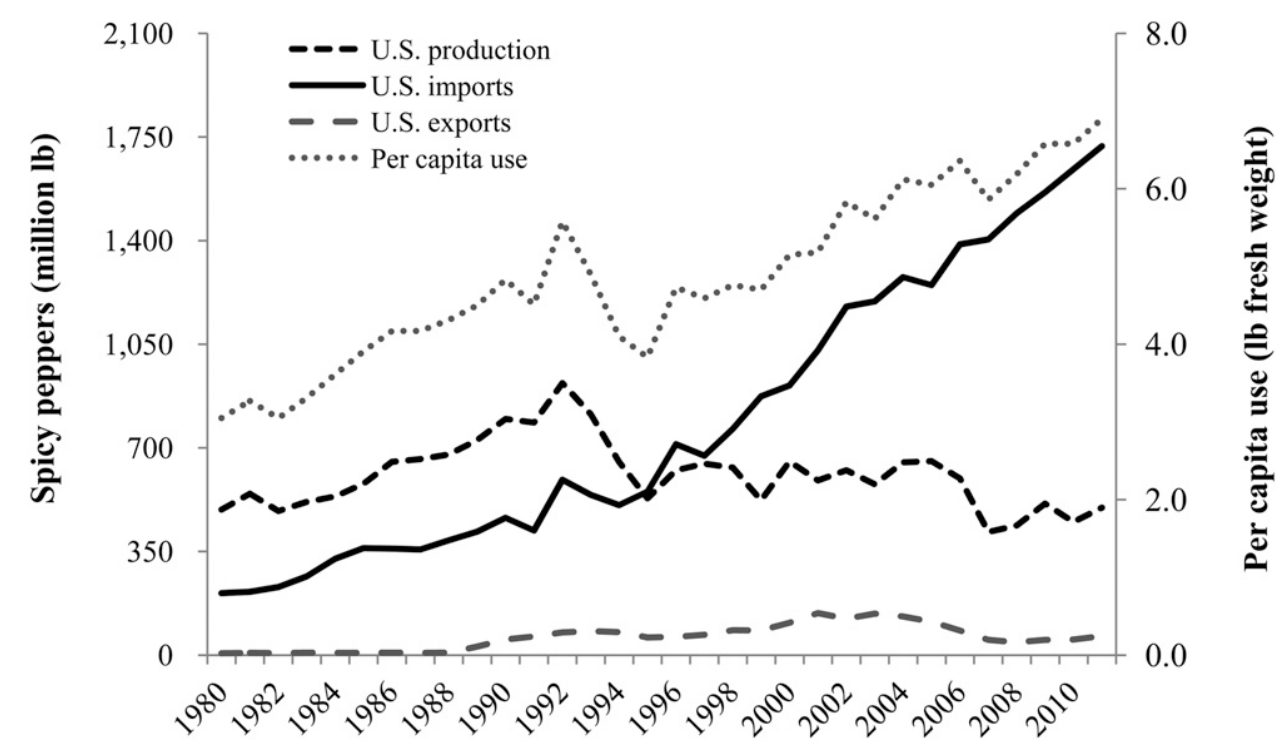

Fig. 1. U.S. spicy pepper trade and per capita consumption of spicy peppers, 1980-2011 (USDA, 2012); $1 \mathrm{lb}=0.4536 \mathrm{~kg}$. 
the southwestern United States) to clarify the difference between chile peppers and spicy peppers in general (Fig. 2). Survey participants were also provided images of peppers, along with their common names, to denote the types of peppers considered as spicy peppers for the purposes of this study. Although the anaheim type of spicy pepper is grown in New Mexico and California, pepper aficionados differentiate between the production from each area. Differences in climate and growing conditions purportedly change the flavor and SHU contained in the pepper. For this reason, the term anaheim is commonly used to refer to the pepper type cultivated in California, while the term New Mexico long green or red chile is used to describe the pepper type cultivated in New Mexico. Respondents were provided images for clarification (Fig. 2).

To explore the relationship between spicy pepper likers and those interested in food (foodies), the survey tool asked respondents to selfidentify in several categories. The term foodie-defined as a person "with a passion for eating and learning about food" (Cairns et al., 2010)—was used to identify those respondents who may pursue a broad range of new foods (Table 2). Following terminology adopted by Tornwall et al. (2012), respondents were categorized as either "likers" or "non-likers" of spicy foods. Similar to Rozin and Schiller (1980), respondents who self-reported they "enjoy some" or "love" spicy foods were considered spicy pepper "likers." Those who reported they "don't like or dislike," "dislike," or "hate" spicy foods were considered spicy pepper "non-likers." Survey participants were also asked to disclose their familiarity with the southwestern United States (defined as the states of New Mexico, Texas, and Arizona), as this may influence participants' familiarity with and preference for spicy peppers, often consumed in Mexican and Mexican American cuisine. Familiarity with the region was measured using one of three metrics: having lived in the area, having family or friends living in the area, or having traveled through the area. As many Hispanic foods incorporate spicy peppers, it was hypothesized that there may be a difference between Hispanics and non-Hispanics in their preferences toward spicy peppers. In addition, those respondents who selfidentified as Hispanic may play a role in "liker" or "non-liker" status. Since Hispanics are the fastest growing segment of the U.S. population, this group of food consumers represent a potential target market for spicy peppers if they are more likely to consume them. For these reasons, consumers who self-identified as Hispanic or Latino (sample size $=44$ ) were identified as "Hispanic" for analytical purposes, whereas those who self-identified as any other race were considered non-Hispanic.

For analysis, raw data from the Web-based survey was collected using an electronic spreadsheet program. Open-ended and categorical questions (e.g., multiple choice questions)

\section{In this section, we're going to discuss how the term "chile pepper" is used in the Southwest.}

The term "chile pepper" is used throughout the remainder of this survey to describe a New Mexico-type chile pepper in several forms and colors. Chile peppers are grown in many countries around the world. Chile peppers can be harvested when they are immature and the color is green. Green chile peppers sold in the U.S. are commonly produced in the United States or Mexico.

If left on the vine, the chile pepper matures and turns red. Red chile peppers sold in the U.S. are commonly grown in the U.S., Mexico, and other parts of the world, such as China and India.

After it is harvested, the chile can be processed and sold in a variety of forms. For example, the red version of the chile pepper (often called "red chile") can be sold frozen, canned, jarred in puree form or dried, where it can be sold in pods, roughly chopped into red chile pepper flakes, or finely ground into chile powder. The green version of the chile pepper (often called "green chile") is typically sold fresh (whole), or is roasted, peeled, and roughly chopped. Chopped green chile can be sold frozen, canned or jarred. Chile peppers can be used in a variety of foods: as an ingredient in Mexican dishes (such as rellenos or enchiladas), hot sauces, toppings, or flavor enhancer.

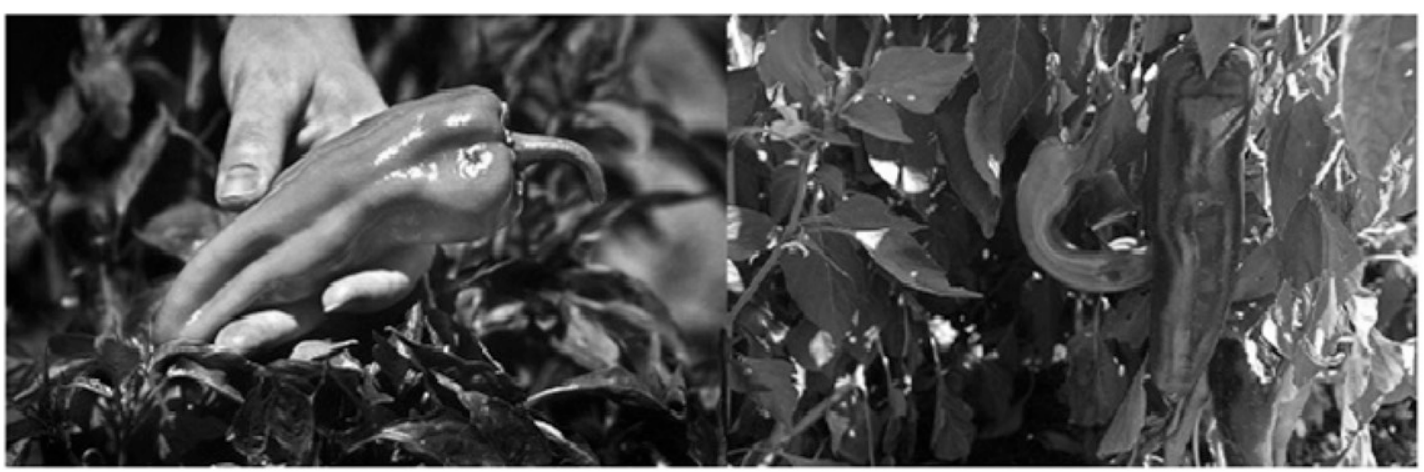

Fig. 2. Information provided to respondents to a Web-based survey of potential U.S. spicy pepper consumers to clarify the term "chile pepper." 
Table 2. Statements used in Web-based survey of potential spicy pepper consumers to measure respondents' familiarity with cooking and food.

\begin{tabular}{|c|c|c|c|c|c|c|}
\hline & \multicolumn{5}{|c|}{ Respondents (\%) } & \multirow{2}{*}{$\begin{array}{c}\text { Total responses } \\
\text { (No.) }\end{array}$} \\
\hline & Strongly disagree & Disagree & Neutral & Agree & Strongly agree & \\
\hline I enjoy preparing meals at home. & 3.0 & 5.9 & 18.3 & 41.3 & 31.4 & 1091 \\
\hline I don't know how to cook. & 57.0 & 23.8 & 11.2 & 4.9 & 3.1 & 1079 \\
\hline $\begin{array}{l}\text { Most of my at-home meals are } \\
\text { prepared by someone else or } \\
\text { purchased (such as a frozen dinner). }\end{array}$ & 39.9 & 26.6 & 17.4 & 9.5 & 6.6 & 1092 \\
\hline $\begin{array}{l}\text { I try to use unique, gourmet, new, } \\
\text { or exotic ingredients in my cooking. }\end{array}$ & 9.8 & 17.7 & 37.9 & 25.7 & 9.0 & 1091 \\
\hline
\end{tabular}

were numerically coded. Simple descriptive statistical analysis (e.g., frequency tables, means) and $\chi^{2}$ tests were performed on the data using SAS statistical analysis software (version 9.2; SAS Institute, Cary, NC).

\section{Results and discussion}

Responses were received from all 50 states. A majority of respondents $(85 \%)$ indicated that they were the primary decision maker in their household for food purchases. As some respondents declined to answer some questions, sample size $(n)$ varied among questions/analyses; however, unless otherwise stated, $n=1104$.

Chi-square tests comparing frequencies of demographic variables commonly reported at a national level suggest that some groups of survey respondents diverged from the general U.S. population [e.g., age, region, income, marital status, and race (Table 3)]. This fact may be explained by several factors relating to the survey methodology. To comply with institutional review board policy, respondents were provided information regarding the purpose of the survey (i.e., gaining insights into consumer preferences for spicy peppers) and given the opportunity to decline participation if they were not interested in the topic. As a result of this policy, it is possible, and even likely, that survey participants had some affinity to spicy peppers and/or spicy foods. As spicy food consumers are a subset of the U.S. population, it is not surprising that some demographic groups differed between the sample and the population. Similarly, the survey protocol required all participants to be at least 18 years of age, which would result in some disparity between the sample frequency for age and that observed in age frequencies for the general population. It is valuable to explore the information gained from this survey as the respondents may be representative of spicy food eaters or those interested in spicy food. Further research, as discussed later in the manuscript, should be conducted to confirm the findings presented here.

Respondents reported mixed feelings regarding spicy foods in general (Fig. 3), which is not surprising as this disparity is documented in the literature (e.g., Rozin and Schiller, 1980; Tornwall et al., 2012). That the majority of respondents $(74 \%)$ enjoy at least some spicy foods is also not surprising, given national trends toward spicy food consumption (Josiam and Monteiro, 2004). While some people may never become spicy pepper consumers, others may become more interested in consuming them over time, given appropriate environmental and social factors (Ludy and Mattes, 2012). To gain a more holistic understanding of respondents' attitudes toward food and cooking, participants were asked to rate their agreement with a series of statements on the topic. The majority of respondents appeared comfortable in the kitchen, while almost half $(47.5 \%)$ self-identified as foodies (Table 2).

Survey respondents reported that they purchased the majority of their fresh, canned, and frozen vegetables at supermarkets $[79 \%$ on average (Fig. 4)]. These results support previous market research in Canada, which suggests supermarkets are preferred over roadside stands or farmers' markets as a spicy pepper purchase location (Mohammed et al., 1993). Consumers participating in this survey purchased almost twice as many fresh vegetables as canned or frozen (Fig. 5 ). These purchase behaviors may vary by produce type: additional research is needed to explore whether these purchasing habits vary by spicy pepper type and processing level (e.g., fresh, frozen).

Fresh spicy peppers were widely purchased by participating food consumers. Despite U.S. outbreaks of Salmonella linked to serrano and jalapeño peppers in 2008 (U.S. Department of Health and Human Services, 2008), these types were still consumed by some respondents, with $57.5 \%$ of respondents having purchased a jalapeño pepper in the past 3 months (Fig. 6 ). In the early 1980s, jalapeños were growing in popularity in the United States (Rowland et al., 1983), yet there is little current data to assess their continued popularity relative to the findings of this study. Although some recent U.S. trade data are available for imports of dried jalapeños (USDA, 2008), it does not present a comprehensive picture of jalapeño consumption patterns since domestic production or fresh imports of this type are not included. Moreover, trade data only indicates imports of two types (jalapeño and anaheim), and does not address domestic production and consumption of multiple types. The results of this study provide a more inclusive, demand-based assessment of consumption of fresh jalapeño and other types These findings also corroborate previous consumer preference research in Mexico, which found that jalapeños are preferred over serrano peppers in Mexican markets (Castellon-Martinez et al., 2012).

More than one-third $(34.9 \%)$ of respondents had not purchased one 
Table 3. Selected demographics of respondents to a Web-based survey of potential U.S. spicy pepper consumers as compared with the U.S. population.

\begin{tabular}{|c|c|c|c|}
\hline Demographic variable & $\begin{array}{l}\text { Total responses } \\
(\text { No. })^{\mathrm{z}}\end{array}$ & $\begin{array}{c}\text { Respondents } \\
(\%)\end{array}$ & $\begin{array}{l}\text { U.S. population } \\
(\%)^{\mathrm{y}, \mathrm{x}}\end{array}$ \\
\hline \multicolumn{4}{|l|}{ Age } \\
\hline Under 20 years of age & 31 & 2.8 & 26.6 \\
\hline $20-34$ years of age & 191 & 17.4 & 20.4 \\
\hline $35-54$ years of age & 406 & 37.0 & 27.4 \\
\hline $55-64$ years of age & 137 & 12.5 & 12.2 \\
\hline 65 years of age or older & 331 & 30.2 & 13.3 \\
\hline Total & 1,096 & 100.0 & 99.9 \\
\hline \multicolumn{4}{|l|}{ Gender } \\
\hline Female & 571 & 52.1 & 50.8 \\
\hline Male & 525 & 47.9 & 49.2 \\
\hline Total & 1,096 & 100.0 & 100.0 \\
\hline \multicolumn{4}{|l|}{ U.S. geographic region } \\
\hline Northeast & 198 & 18.1 & 18.1 \\
\hline Midwest & 288 & 26.3 & 21.6 \\
\hline South & 394 & 35.9 & 37.0 \\
\hline West & 216 & 19.7 & 23.4 \\
\hline Total & 1,096 & 100.0 & 100.1 \\
\hline \multicolumn{4}{|l|}{ Household income } \\
\hline Less than $\$ 24,999$ & 269 & 24.5 & 25.0 \\
\hline$\$ 25,000-\$ 49,999$ & 376 & 34.3 & 24.5 \\
\hline$\$ 50,000-\$ 99,999$ & 337 & 30.7 & 29.7 \\
\hline$\$ 100,000-\$ 149,999$ & 81 & 7.4 & 12.1 \\
\hline$\$ 150,000$ or more & 33 & 3.0 & 8.7 \\
\hline Total & 1,096 & 100.0 & 100.0 \\
\hline \multicolumn{4}{|l|}{ Marital status } \\
\hline Cohabiting $^{\mathrm{w}}$ & 15 & 1.4 & - \\
\hline $\begin{array}{l}\text { Divorced, widowed, } \\
\text { or separated }\end{array}$ & 241 & 22.0 & 19.2 \\
\hline Married & 568 & 51.8 & 48.3 \\
\hline Single & 272 & 24.8 & 32.5 \\
\hline Total & 1,096 & 100.0 & 100.0 \\
\hline \multicolumn{4}{|l|}{ Race } \\
\hline $\begin{array}{l}\text { American Indian or } \\
\text { Alaska Native }\end{array}$ & 11 & 1.0 & 0.7 \\
\hline Asian & 41 & 3.7 & 4.8 \\
\hline Black or African American & 83 & 7.6 & 12.2 \\
\hline Hispanic or Latino & 44 & 4.0 & 16.7 \\
\hline $\begin{array}{c}\text { Native Hawaiian or } \\
\text { Pacific Islander }\end{array}$ & 5 & 0.5 & 0.2 \\
\hline White or Caucasian & 903 & 82.4 & 63.3 \\
\hline Other & 9 & 0.8 & 2.1 \\
\hline Total & 1,096 & 100.0 & 100.0 \\
\hline
\end{tabular}

${ }^{\mathrm{z}}$ Totals do not equal 1104 as not all survey respondents chose to answer demographic questions.

${ }^{y}$ May not sum to $100 \%$ due to rounding.

'U.S. Census Bureau (2012).

${ }^{\text {w}}$ Category not used by the U.S. Census Bureau (2012).

of the five fresh spicy pepper types studied in the past 3 months (Fig. 6). Of the 384 survey participants who had not purchased fresh spicy peppers recently, almost half $(42.7 \%)$ were self-professed "likers" of spicy foods. These respondents could represent growth opportunities in the U.S. fresh spicy pepper market. The popularity of a specific spicy pepper type did not appear heavily influenced by the type's pungency. For example, poblanos are one of the mildest fresh peppers examined in this study $[\approx 1369$ SHU (Orellana-Escobedo et al., 2012)], yet they were purchased the least.

Paprika powder, a relatively mild spicy pepper product [0-300 SHU (Coon et al., 2008)], was the most widely consumed dried or ground pepper of the seven studied. However, almost one-quarter $(22.7 \%)$ of respondents had not consumed a dried or ground spicy pepper in the past 3 months (Fig. 7). Of the 250 survey participants who had not purchased dried or ground spicy peppers recently, more than one-third (40.4\%) were self-professed "likers" of spicy foods. These respondents could also represent growth opportunities in the U.S. dried or ground spicy pepper market.

More than half $(56.6 \%)$ of the consumers had not consumed any of the four studied processed spicy pepper products in the past 3 months (Fig. 8). Of the 625 survey participants who had not recently purchased any of the four processed spicy pepper products used in this study, more than half $(61.8 \%)$ were self-professed "likers" of spicy foods. Again, this consumer segment may represent a potential marketing opportunity for spicy pepper processors, if nonconsumers of these products can be transformed into consumers. However, increased shelf life of processed chile peppers may contribute to the observed purchased infrequency. Further research is needed to explore the potential for increased shelf life to contribute to purchase infrequency. In addition, research needs to be conducted to determine whether these consumers do not consume any processed spicy pepper products, or merely the examples identified in this study. Additional education about how to use the processed spicy pepper products at home or the value added by processing (e.g., time saved by purchasing roasted and peeled chile peppers in a can or jar), may be required to capitalize on this potential market. Mexican food consumers report that they like spicy peppers because of their flavor-adding properties (Rozin and Schiller, 1980). It is possible that some U.S. spicy pepper "non-likers" can become "likers" if given the opportunity to experience this flavorenhancing quality for themselves.

More than one-third of respondents (37.0\%) purchased fresh (whole, raw or roasted) spicy peppers once per month or more frequently $[n=1101$ (Fig. 9)]. In a small study of American consumers conducted in 1980, the average participant purchased (consumed) chile peppers 2.62 times per week (Rozin and Schiller, 1980); more recent studies are not available. While national spicy pepper per capita 


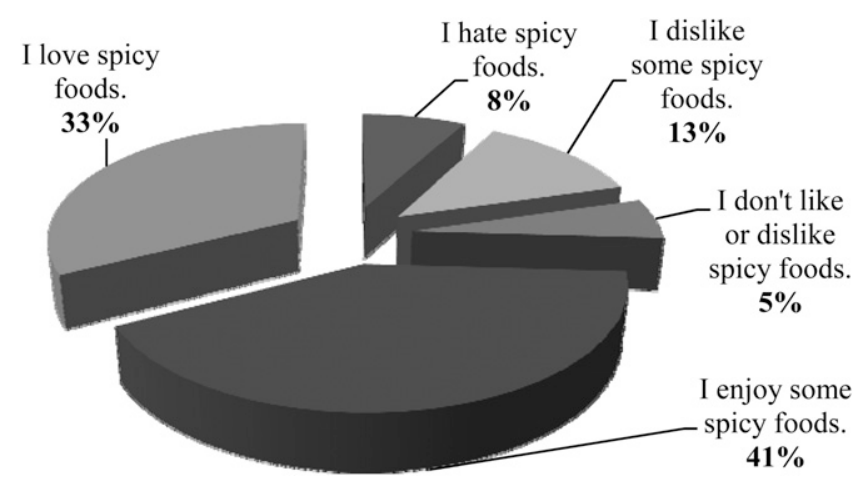

Fig. 3. Preferences of respondents to a Web-based survey of potential U.S. spicy pepper consumers toward spicy foods (sample size $=1096)$.

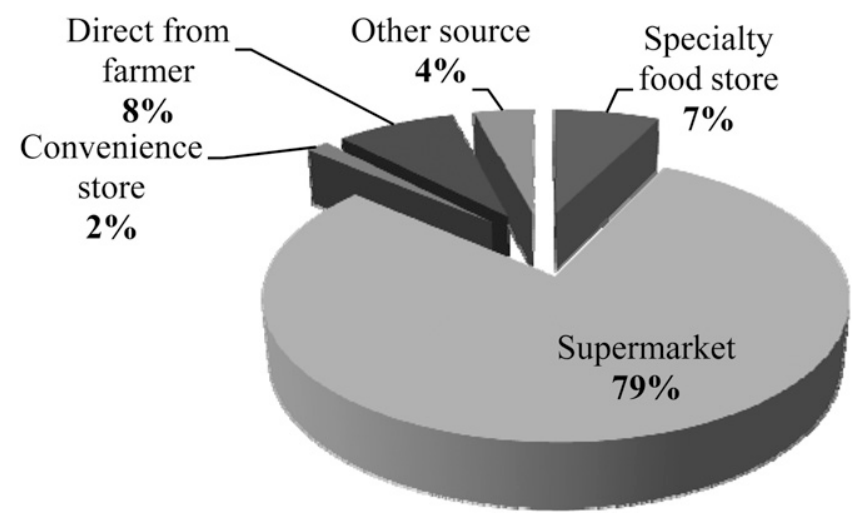

Fig. 4. Percent of vegetables purchased by respondents to a Web-based survey of potential U.S. spicy pepper consumers at specific shopping locations (sample size = 1104).
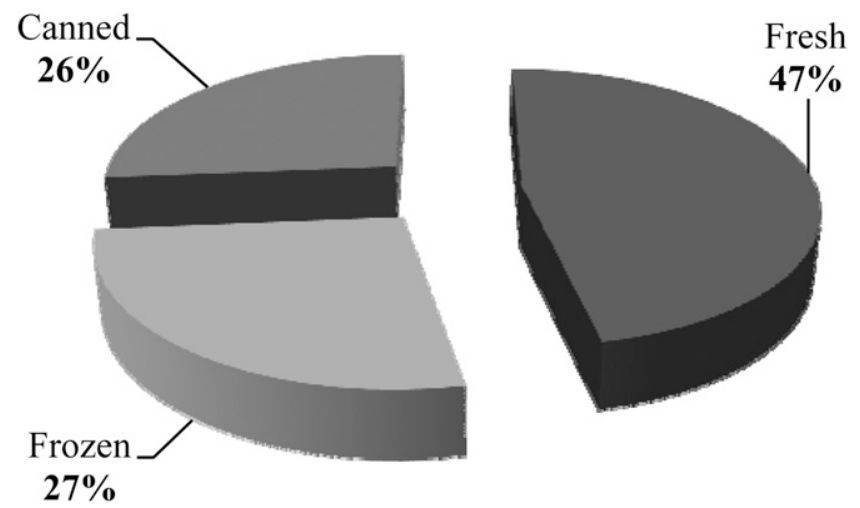

Fig. 5. Types of vegetables purchased by respondents participating in a Web-based survey of potential U.S. spicy pepper consumers (sample size $=1104)$.

consumption is available (USDA, 2008), more recent purchase frequency data for individual spicy pepper types are not. This is likely due to the large number of types of spicy peppers and the difficulty of distinguishing various groups for survey purposes. Our work attempts to make these distinctions and offer a contribution to the literature available on this topic. In general, it appears respondents prefer to consume spicy peppers fresh, with more infrequent consumption of processed spicy peppers (dried, ground, flaked, in a can or jar). Frozen spicy peppers appear less popular among respondents, although this may be related to availability. Anecdotal evidence suggests frozen spicy peppers are not widely available throughout the United States.
Of the 1096 respondents who reported demographic information, one-quarter $(25.9 \%)$ were considered spicy pepper "non-likers." Demographic differences between "likers" and "non-likers," explored using $\chi^{2}$ tests of proportion, are reported in Table 4. Women appear more likely to be "non-likers" of spicy foods than men $(P=0.05)$. This finding conflicts with earlier research conducted by Ludy and Mattes (2012), where no difference was found between the sexes with regard to a preference toward spicy foods. It also appears that those participants with ties to the southwestern United States are more likely to be "likers" of spicy foods than consumers who do not have ties to the southwestern United States $(P=0.03)$. There was no significant difference $(P=0.83)$ in the proportion of non-Hispanic and Hispanic respondents who reported they like spicy peppers. In addition, it appears that percent "likers" increased with income, but further research is needed to explore this relationship in further detail (Table 4). This finding substantiates previous U.S. spicy pepper consumer research (Kresin, 2012).

While some research has explored U.S. spicy pepper consumers and consumption trends collectively and in general terms (e.g., Kresin, 2012), little formal, publically available market research has explored U.S. spicy pepper consumers in depth, including detailed demographic characteristics and shopping behaviors related to the individual types of peppers they consume. This study explored consumers' stated shopping behaviors related to spicy peppers using a quantitative online survey methodology. Responses of this survey group suggest that many consumers enjoy spicy peppers and that consumption varies by pepper type. In addition, popularity of pepper type varies by form: for example, jalapeño peppers were identified as the most popular form of spicy pepper when consumed fresh, but paprika and green chile (New Mexico-type long green chile) were consumed more frequently when processed (dried or canned). These results also suggest that the most popular pepper types are not necessarily the "hottest" or "mildest" of those available in the market. The popularity or frequency of spicy pepper use differed among 


\section{Research Reports}

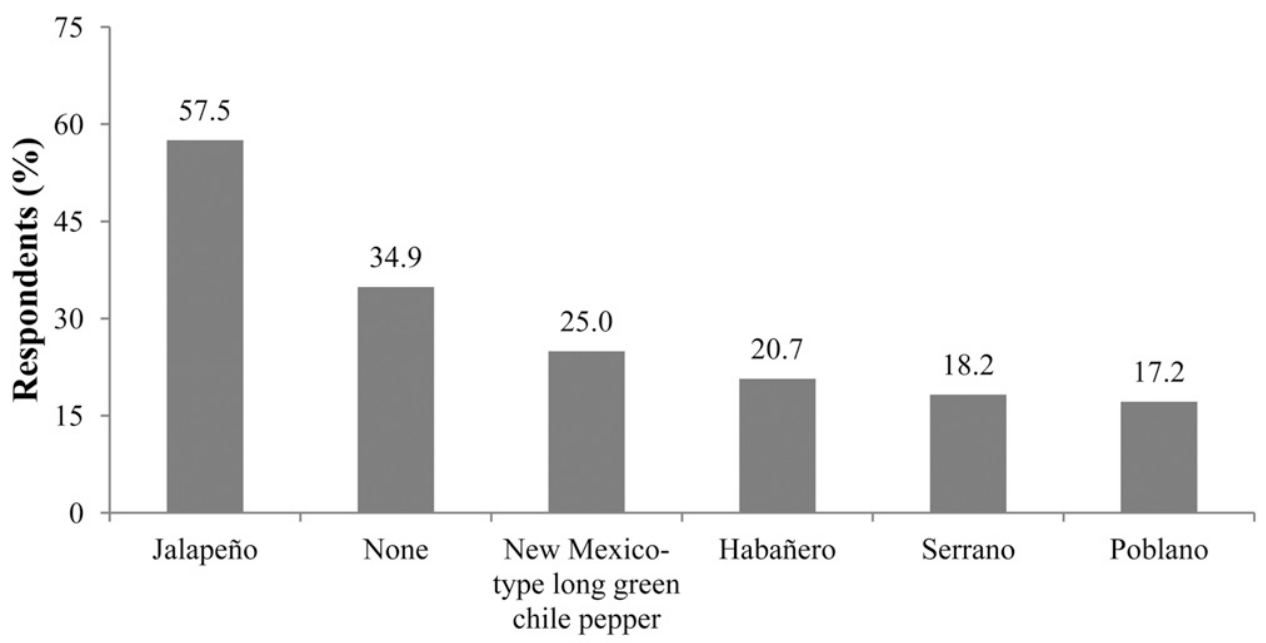

Spicy pepper type

Fig. 6. Types of fresh spicy peppers purchased in the past 3 months by respondents participating in a Web-based survey of potential U.S. spicy pepper consumers (sample size $=1102)$.

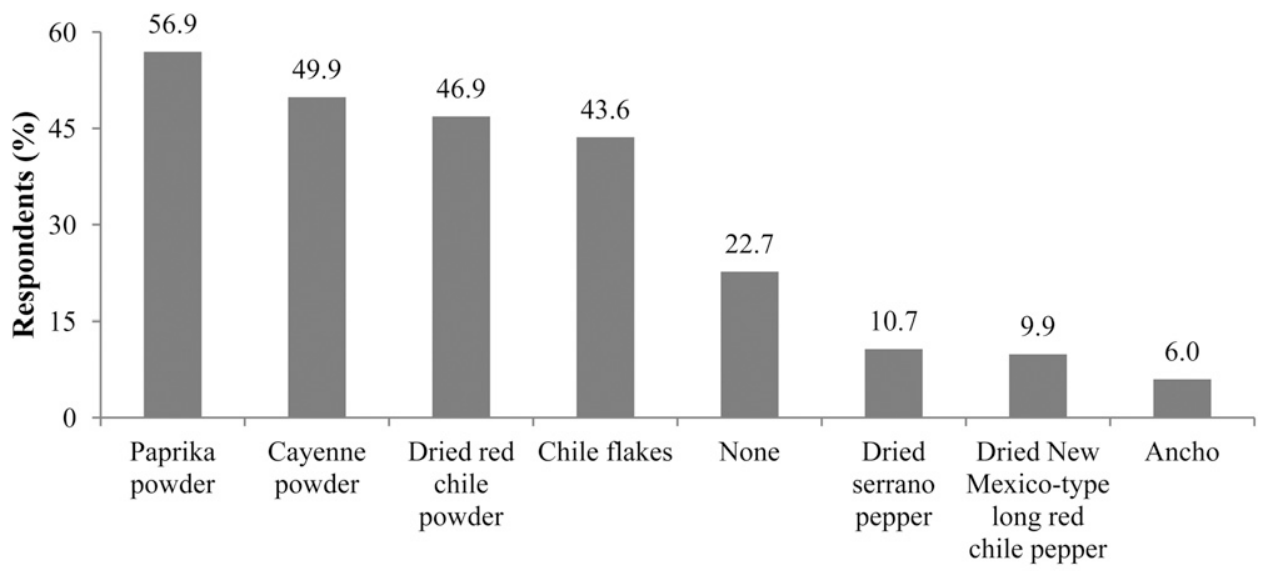

Spicy pepper product

Fig. 7. Types of dried and ground spicy peppers purchased in the past 3 months by participants in a Web-based survey of potential U.S. spicy pepper consumers (sample size $=1103)$.

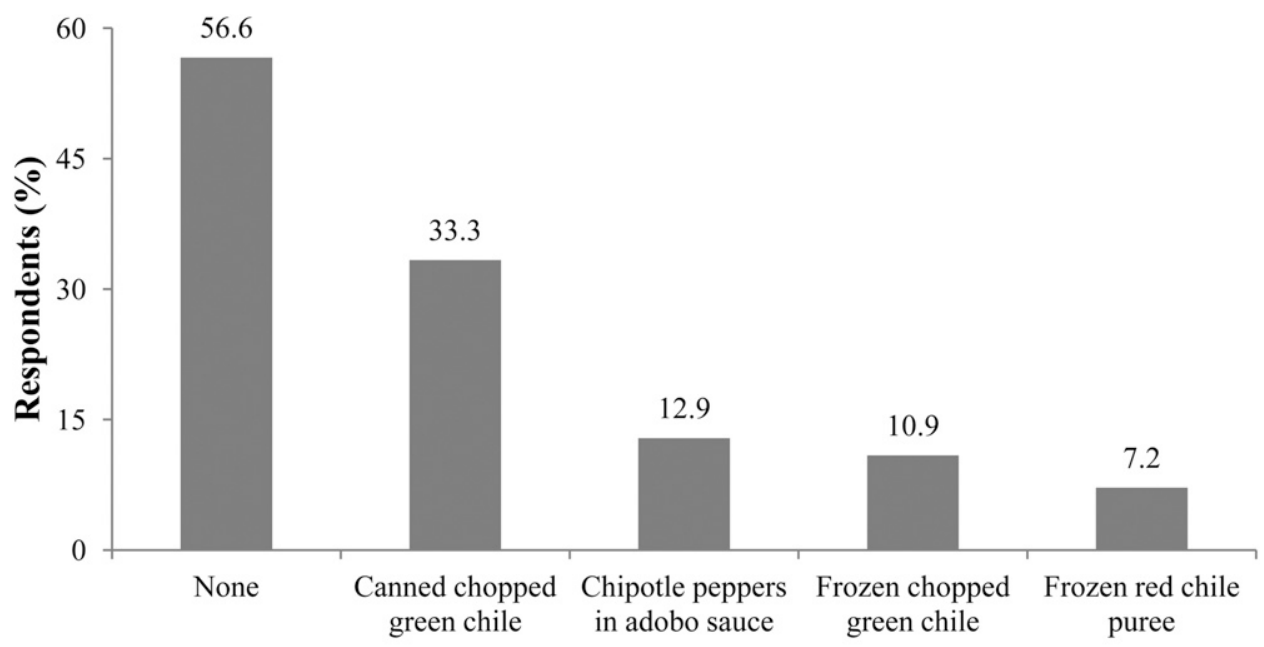

Spicy pepper product

Fig. 8. Types of processed spicy pepper products purchased in the past 3 months by respondents completing a Web-based survey of potential U.S. spicy pepper consumers ( sample size $=1104)$. 


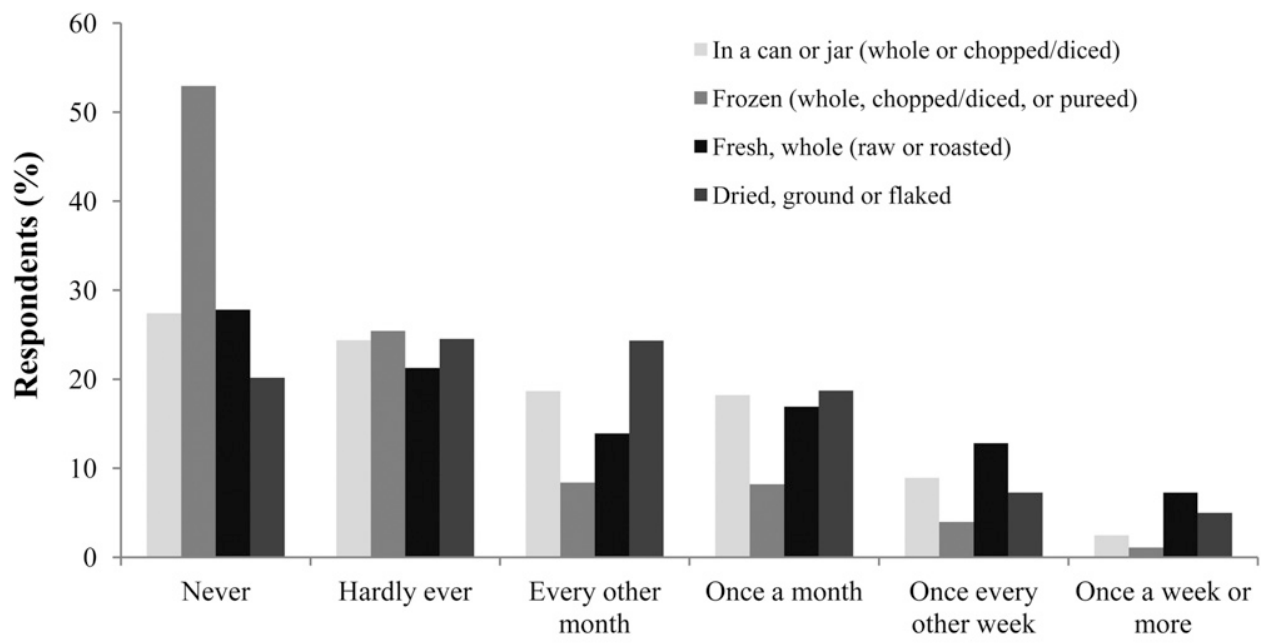

Purchase frequency reported

Fig. 9. Purchase frequency of specific pepper types by respondents to a Web-based survey of potential U.S. spicy pepper consumers (sample size $=1086-1101)$.

Table 4. Comparisons between respondents to a Web-based survey who self-identified as spicy pepper likers and non-likers ( sample size $=1096)$.

\begin{tabular}{|c|c|c|c|c|c|}
\hline \multicolumn{2}{|c|}{ Demographic variable } & \multirow{2}{*}{$\begin{array}{c}\text { Spicy pepper } \\
\text { likers }(\%)^{\mathrm{z}} \\
76.8\end{array}$} & \multirow{2}{*}{$\begin{array}{c}\begin{array}{c}\text { Spicy pepper } \\
\text { non-likers }(\%)^{z}\end{array} \\
23.2\end{array}$} & \multirow{2}{*}{$\frac{\chi^{2}}{3.75}$} & \multirow{2}{*}{$\frac{\text { P value }}{0.05}$} \\
\hline Gender & Male & & & & \\
\hline Ties to southwestern & Yes & 76.0 & 24.1 & 4.51 & 0.03 \\
\hline United State & No & 69.9 & 30.2 & & \\
\hline \multirow[t]{3}{*}{ Age } & Under 20 years of age & 87.1 & 12.9 & 8.50 & 0.07 \\
\hline & $55-64$ years of age & 70.8 & 29.2 & & \\
\hline & 65 years of age or older & 70.1 & 29.9 & & \\
\hline \multirow[t]{3}{*}{ Income } & Less than $\$ 24,999$ & 67.3 & 32.7 & 12.13 & 0.02 \\
\hline & $\$ 25,000-\$ 49,999$ & 73.9 & 26.1 & & \\
\hline & $\$ 50,000-\$ 99,999$ & 76.9 & 23.2 & & \\
\hline
\end{tabular}

${ }^{\mathrm{z}}$ May not total $100 \%$ due to rounding.

demographic groups. For example, men were more likely to indicate a preference for spicy peppers. Similarly, individuals with ties to the southwestern United States (e.g., family or friends living in the southwestern United States) are more likely to purchase spicy peppers.

The examination of spicy pepper consumption described in this study suggests opportunities for increasing markets. For example, a significant percentage of surveyed consumers (43\% for fresh spicy peppers and $62 \%$ for processed spicy peppers) that indicated they had not recently purchased pepper products were self-proclaimed "likers" of spicy peppers. Additional research regarding why these individuals do not purchase spicy peppers more frequently should be conducted. Further research using revealed preference data (e.g., buying experiments, scanner data) may be conducted to support the results seen in this study. Future work could also explore what pepper attributes (e.g., pungency level, freshness) are most important to U.S. consumers, and how the importance of these attributes varies among the numerous spicy pepper types available to consumers.

\section{Literature cited}

Bosland, P.W., D. Coon, and G. Reeves. 2012. 'Trinidad Moruga Scorpion' pepper is the world's hottest measured chile pepper at more than two million Scoville heat units. HortTechnology 22:534-538.

Cairns, K., J. Johnston, and S. Baumann. 2010. Caring about food: Doing gender in the foodie kitchen. Gender Soc. 24(5):591-615.

Castellon-Martinez, E., J.L. Chavez-Servia, J.C. Carrillo-Rodriguez, and A.M. VeraGuzman. 2012. Consumption preferences for pepper (Capsicum annumm L.) landraces in the central valleys of Oaxaca, Mexico. Revista Fitotecnia Mexicana 35(5):27-35. 
Chile Pepper Institute. 2006. Chile heat. 22 July 2013 . <http://www. chilepepperinstitute.org/content/files/ educ_info/ChileHeat.pdf>.

Collins, M.D., L.M. Wasmund, and P.W. Bosland. 1995. Improved method for quantifying capsaicinoids in Capsicum using high-performance liquid chromatography. HortScience 30:137-139.

Coon, D., E. Votava, and P.W. Bosland. 2008. The chile cultivars of New Mexico State University. New Mexico Agr. Expt. Sta. Res. Rpt. 763.

Couper, M. 2001. Web survey research: Challenges and opportunities. Proc. Annu. Mtg. Amer. Stat. Assn., Amer. Stat. Assn., Alexandria, VA.

Evans, J.R. and A. Mathur. 2005. The value of online surveys. Internet Res. 15(2):195-219.

Josiam, B.M. and P.A. Monteiro. 2004. Tandoori tastes: Perceptions of Indian restaurants in America. Intl. J. Contemporary Hospitality Mgt. 16(1):18-26.

King, L., L. Wuensch, and A. Hess. 2010. Spices as superfoods: Past, present, and future. 22 July 2013. <http://www. mnsna.org/wp-content/uploads/2010/ 07/Super-7-McCormick-NutritionConference-Presentation.pdf $>$.

Klontz, K.C., J.C. Klontz, R.K. Mody, and R.M. Hoekstra. 2010. Analysis of tomato and jalapeño and serrano pepper imports into the United States from Mexico before and during a national outbreak of Salmonella serotype saintpaul infections in 2008. J. Food Prot. 73: 1967-1974.

Kresin, J.M. (ed.). 2012. Fresh trends 2012. Packer 119(53):65.

Ludy, M. and R.D. Mattes. 2012. Comparison of sensory, physiological, personality, and cultural attributes in regular spicy food users and non-users. Appetite $58(1): 19-27$

Miller, T.W. and P.R. Dickson. 2001 On-line market research. Internet J. Electronic Commun. 4(3):139-167.

Mohammed, M., L.A. Wilson, and P.I. Gomes. 1993. Consumer attitudes, preferences and shopping behavior toward hot peppers imported from Trinidad and Tobago. J. Food Qual. 16(2):109-123.

Orellana-Escobedo, L., L.E. GarciaAmezquita, G.I. Olivas, J.J. Ornelas-Paz, and D.R. Sepulveda. 2012. Capsaicinoids content and proximate composition of Mexican chili peppers (Capsicum spp.) cultivated in the state of Chihuahua. CyTA J. Food 11(2):179-184.

Rowland, B.J., B. Villalon, and E.E. Burns. 1983. Capsaicin production in sweet bell and pungent jalapeño peppers. J. Agr. Food Chem. 31(3):484-487.

Rozin, P. and D. Schiller. 1980. The nature and acquisition of a preference for chili pepper by humans. Motiv. Emot. 4(1):77-101.

Sheehan, K.B. 2002. Online research methodology: Reflections and speculations. J. Interactive Advertising 3(1):56-61.
Tornwall, O., K. Silventoinen, J. Kaprio, and H. Tuorila. 2012. Why do some like it hot? Genetic and environmental contributions to the pleasantness of oral pungency. Physiol. Behav. 107(3):381-389.

U.S. Census Bureau. 2012. Population finder, various states and categories, 2010-2012. 22 July 2013. <http://www. census.gov>.

U.S. Department of Agriculture. 2008. U.S. bell \& chile pepper statistics - Nov. 2008. 22 July 2013. <http://usda. mannlib.cornell.edu/MannUsda / viewDocumentInfo.do?documentID= 1659>.

U.S. Department of Agriculture. 2012. 2012 Vegetables and pulses yearbook (Table 46). 22 July 2013. <http://usda. mannlib.cornell.edu/MannUsda/ viewDocumentInfo.do?documentID= 1858>.

U.S. Department of Health and Human Services. 2008. Outbreak of Salmonella serotype saintpaul infections associated with multiple raw produce items - United States, 2008. Morb. Mortal. Wkly. Rpt. 57(34):1.

Wright, K.B. 2005. Researching internetbased populations: Advantages and disadvantages of online survey research, online questionnaire authoring software packages and web survey services. J. ComputerMediated Commun. 10(3). 12 Sept. 2013. <http://onlinelibrary.wiley.com/ doi/10.1111/j.1083-6101.2005.tb00259. $\mathrm{x} /$ full $>$. 